\title{
PERMANÊNCIA DE ALUNOS NA MODALIDADE A DISTÂNCIA: DESAFIO NA FORMAÇÃO DE GESTORES EM SAÚDE*
}

\author{
Ricardo Bezerra Cavalcante ${ }^{1}$, Fabricia Almeida Diniz ${ }^{2}$, Patrícia Peres de Oliveira ${ }^{3}$, Humberto Ferreira de \\ Oliveira Quites ${ }^{4}$, Richardson Miranda Machado ${ }^{5}$, Tarcísio Laerte Gontijo ${ }^{6}$
}

RESUMO: Estudo de caso com abordagem qualitativa, que buscou analisar a permanência de alunos em um curso de especialização de Gestão em Saúde na modalidade a distância, em uma Instituição de Ensino Superior. Participaram 59 alunos, vinculados a polos de apoio presencial em Minas Gerais e São Paulo, que responderam a entrevista semiestruturada e um questionário on-line, em agosto de 2014. Utilizou-se a Análise de Conteúdo Temático-Categorial e estatística descritiva simples. Como referencial teórico, utilizou-se o Modelo final para análise da permanência de alunos em cursos na modalidade a distância. Verificou-se que apoio familiar, trabalho, interação com a tutoria e habilidade com os recursos tecnológicos favoreceram a permanência. Uma estrutura acadêmica adequada, associada à credibilidade da instituição proponente e o compromisso do aluno, catalisaram a permanência. Conclui-se que a formação de gestores em saúde, por meio da modalidade a distância, exige considerar os múltiplos fatores que influenciam a permanência.

DESCRITORES: Tecnologia da Informação; Educação à Distância; Gestão em Saúde; Formação profissional em saúde; Educação continuada.

\section{STUDENT PERMANENCE IN DISTANCE EDUCATION: A CHALLENGE IN HEALTH MANAGERS' TRAINING}

ABSTRACT: Case study with a qualitative approach, aiming to analyze students' permanence in a specialization course in Health Management in the distance education modality, offered at a higher education institution. The participants were 59 students affiliated with in-class support hubs in Minas Gerais and São Paulo, who answered the semistructured interview and an online questionnaire in August 2014. Thematic-Categorical Content Analysis and simple descriptive statistics were used. As the theoretical framework, the final model to analyze students' permanence in distance education courses was used. It was verified that family support, work, interaction with the tutor and technological skills favored the permanence. An appropriate academic structure, associated with the credibility of the proponent institution and the student's commitment catalyzed the permanence. It is concluded that health managers' training in distance education requires that the multiple factors that influence this permanence be taken into account. DESCRIPTORS: Information Technology; Education, Distance; Health Management; Health human resource training; Education, continuing.

\section{PERMANENCIA DE ALUMNOS EN LA MODALIDAD A DISTANCIA: RETO EN LA FORMACIÓN DE GESTORES EN SALUD}

RESUMEN: Estudio de caso con aproximación cualitativa, que buscó analizar la permanencia de alumnos en un curso de especialización de Gestión en Salud en la modalidad a distancia en una Institución de Educación Superior. Participaron 59 alumnos, vinculados a polos de apoyo presencial en Minas Gerais y São Paulo, que contestaron una entrevista semiestructurada y un cuestionario en línea en agosto del 2014. Fue utilizado el análisis de Contenido Temático-Categorial y estadística descriptiva simple. Como referencial teórico, fue utilizado el Modelo final para análisis de la permanencia de alumnos en cursos a distancia. Se verificó que apoyo familiar, trabajo, interacción con la tutoría y habilidad con los recursos tecnológicos favorecieron la permanencia. Una estructura académica adecuada, asociada a la credibilidad de la institución proponente y el compromiso del alumno, catalizaron la permanencia. Se concluye que la formación de gestores en salud en la modalidad a distancia exige considerar los múltiples factores que influyen en la permanencia.

DESCRIPTORES: Tecnología de la Información; Educación a Distancia; Gestión en Salud; Capacitación de recursos humanos en salud; Educación continua.

\footnotetext{
*Artigo extraído da dissertação intitulada: "Análise da permanência de alunos em um curso de especialização de gestão em saúde na modalidade à distância". Universidade Federal de São João Del Rei, 2015.
}

${ }^{1}$ Enfermeiro. Doutor em Ciência da Informação. Docente de Enfermagem da Universidade Federal de São João Del Rei. Divinópolis, MG, Brasil.

${ }^{2}$ Enfermeira. Mestre em Enfermagem. Universidade Federal de São João Del Rei. Divinópolis, MG, Brasil.

${ }^{3}$ Enfermeira. Doutora em Educação. Docente de Enfermagem da Universidade Federal de São João Del Rei. Divinópolis, MG, Brasil. ${ }^{4}$ Enfermeiro. Doutor em Enfermagem. Docente de Enfermagem da Universidade Federal de São João Del Rei. Divinópolis, MG, Brasil. ${ }^{5}$ Enfermeiro. Doutor em Psiquiatria. Docente de Enfermagem da Universidade Federal de São João Del Rei. Divinópolis, MG, Brasil. ${ }^{6}$ Enfermeiro. Doutor em Ciências da Saúde. Docente de Enfermagem da Universidade Federal de São João Del Rei. Divinópolis, MG, Brasil.

Autor Correspondente:

Recebido: $10 / 11 / 2016$

Ricardo Bezerra Cavalcante

Finalizado: 25/05/2017

Universidade Federal de São João Del Rei

R. Sebastião Gonçalves Coelho, 400 - 35.501-296 - Divinópolis, MG, Brasil

E-mail: ricardocavalcante@ufsj.edu.br 


\section{INTRODUÇÃO}

Diante da necessidade de gestores públicos qualificados, o Ministério da Educação, por meio da Coordenação de Aperfeiçoamento de Pessoal de Nível Superior (CAPES) e Sistema Universidade Aberta do Brasil (UAB), vem desenvolvendo desde 2009 o Programa Nacional de Formação em Administração Pública (PNAP). Este compreende os cursos de bacharelado em Administração Pública, especialização em Gestão Pública, especialização em Gestão Pública Municipal e especialização em Gestão em Saúde(1-2).

Destaca-se que todos os cursos vinculados ao PNAP são ofertados gratuitamente, na modalidade de Ensino a Distância (EaD), buscando a democratização do acesso à educação e diminuindo as barreiras geográficas $^{(1)}$. Sabe-se que a globalização tem contribuído para o crescimento e a credibilidade da $\mathrm{EaD}$, sendo alternativa de ensino que utiliza tecnologias para intermediar o processo de aprendizagem permanente $^{(3)}$.

Apesar da evolução da EaD no Brasil, verificou-se a evasão como um dos principais problemas nessa modalidade e, no PNAP, essa problemática também se faz presente ${ }^{(4-5)}$. Atualmente, além da evasão, vem sendo apontada a necessidade de se compreender a permanência dos estudantes em sua trajetória de educação, seja ela na modalidade presencial ou a distância ${ }^{(6-7)}$.

A permanência é a ação contrária à evasão e que leva à diplomação. Está associada às condições de aprendizagem que se estabelecem, por meio da afetividade e construção do conhecimento, com o suporte da interação nos ambientes virtuais ${ }^{(8)}$. O levantamento de informações sobre características individuais e situacionais dos alunos permanentes pode nortear a construção de ações e estratégias de ensino adequadas ao perfil e às necessidades do público-alvo, o que pode contribuir para a redução da evasão ${ }^{(7)}$.

Justifica-se a necessidade de compreender os fatores influenciadores da permanência, visando propor estratégias de ensino que contemplem contextos de aprendizagem motivadores ${ }^{(7)}$. Assim, questiona-se: "Como a permanência de alunos tem sido influenciada em um curso de especialização de Gestão em Saúde na modalidade a distância?".

\section{- MÉTODOS}

Trata-se de estudo de caso de abordagem qualitativa. Tal abordagem deve-se à necessidade de compreender um fenômeno que está ligado à subjetividade do indivíduo, sua historicidade e relações com o meio ${ }^{(9)}$. Justifica-se a utilização do estudo de caso por ser um referencial metodológico capaz de captar os acontecimentos contemporâneos e significativos da vida real(10). A unidade de análise foi a permanência de alunos em um curso de especialização de Gestão em Saúde na modalidade a distância.

O cenário foi uma Instituição de Ensino Superior (IES) pública que oferta o referido curso em oito polos de apoio presencial, sendo seis no estado de Minas Gerais e dois no estado de São Paulo. O curso é ofertado nesta IES desde 2013. Foram incluídos no estudo os alunos da primeira turma que concluíram o referido curso (aprovados em todas as disciplinas e no Trabalho de Conclusão de Curso - TCC). Foram excluídos os alunos que não compareceram à defesa de TCC, reprovados em alguma disciplina ou que tivessem qualquer pendência que os impossibilitasse de concluir o curso. A partir dos critérios anteriores, dos 320 alunos matriculados no curso, 120 foram considerados concluintes.

No dia da defesa de TCC, no ano de 2014, nos polos de apoio presencial e após a aprovação final, os alunos presentes e que se enquadravam nos critérios foram convidados a participar. Assim, 59 dos 120 alunos concluintes da primeira turma aceitaram participar da pesquisa. Após o aceite, os alunos foram conduzidos a uma sala no polo de apoio presencial, onde entrevistas semi-estruturadas foram realizadas. Posteriormente, foram conduzidos ao laboratório de informática e preencheram um questionário on-line. A coleta foi realizada por oito colaboradores diferentes, devidamente treinados, um em cada polo de apoio.

Ambas as fontes de evidências (entrevista e questionário on-line) foram elaboradas a partir do 
"Modelo final para análise da permanência de alunos em cursos na modalidade a distância" proposto por Silva ${ }^{(8: 212)}$. Deste modelo foram usadas suas três dimensões. Na primeira "Perfil do aluno" são relacionados os componentes: Atributos individuais, Aspectos contextuais, Trabalho e estágio, Contexto familiar, Escolaridade anterior. Na segunda dimensão "Estar-em-rede" os componentes são: Uso de TICs, Interação docente e Interação discente. A última dimensão "Condições de permanência" possui os componentes: compromisso pessoal e credibilidade institucional ${ }^{(8)}$.

Tais dimensões, juntamente com seus componentes, nortearam a categorização dos resultados. O modelo de Silva ${ }^{(8)}$ pode ser dividido em dois: um na modalidade a distância e outro na modalidade presencial. Entretanto, utilizou-se apenas o Modelo teórico que trata da educação a distância, pois esse é o contexto que envolve o curso avaliado.

Os dados provenientes do questionário on-line foram tratados por meio de estatística descritiva simples. Os dados das entrevistas foram analisados segundo a Análise de Conteúdo TemáticoCategorial ${ }^{(11)}$, com suporte do software Atlas Ti. O estudo foi aprovado pelo Comitê de Ética em Pesquisa da Universidade Federal de São João del-Rei, com o parecer de nº 714.635, em 10/07/2014.

\section{- RESULTADOS}

\section{O perfil do egresso}

Sobre os atributos individuais, os alunos foram, em sua maioria, do sexo feminino 40 (69\%), com idade entre 27 e 56 anos (média de 41,5 anos), e predominando a faixa etária entre 40 e 49 anos 20 (35\%). Quanto ao estado civil, eram casados 33 (57\%) e na média 2,1 pessoas residiam numa mesma casa.

O vínculo empregatício em sua maioria foi o público 53 (89\%), existindo também o vínculo empregatício privado seis (11\%). Em relação à sua atuação, 18 (30\%) relataram que atuavam como gestor/administrador em serviços de saúde, sendo que $52(88 \%)$ atuavam de alguma forma no Sistema Único de Saúde. Observou-se que 36 (61\%) possuía um vínculo empregatício e 23 (39\%) dois ou mais vínculos.

Verificou-se que 25 (42,3\%) dos participantes era de enfermeiros, seguidos de dentistas nove (15,2\%) e farmacêuticos seis (10,2\%). A última graduação em rede privada aconteceu em 44 (75\%) entrevistados. Identificou-se que 34 (58\%) dos profissionais entrevistados já possuía pós-graduação.

Quanto ao contexto de estudo do aluno, verificou-se que 35 (60\%) já vivenciou experiências em cursos na modalidade a distância. Trabalharam durante a realização do curso 57 (98\%), e uma pequena parcela relatou a participação em outro curso simultâneo em EaD 20 (34\%). Todos os participantes afirmaram saber utilizar fórum de discussão, e-mail e internet. Sabiam utilizar chats e sala de bate papo 56 (95\%). Todos os alunos estudaram em casa e 33 (56\%) também estudou no local de trabalho. Ainda, 93\% dos alunos apontaram a contribuição de familiares e colegas de trabalho para a realização do curso.

Sobre aspectos contextuais dos participantes, foi identificado que, apesar dos benefícios do curso, este gera impacto na organização das atividades cotidianas e na sua disponibilidade de tempo:

A minha vida é muito tumultuada, então é a falta de tempo [...]. (E1)

Pra você fazer o curso, você tem que tirar um momento para o estudo, e isso acaba que não acontece devido aos afazeres do dia-a-dia [...]. (E28)

Entretanto, estas barreiras não inviabilizaram sua permanência, alguns destacaram suas estratégias para permanecer no curso: a autodisciplina, a organização e a busca de apoio no polo presencial.

Tento me disciplinar, tento fazer uma carga horária por dia ou por semana[...]. (E37)

Acertar a rotina diária, deixar um tempo reservado pra tarefas e fóruns [...]. (E48)

Eu não deixei de procurar no polo para ajuda. Estava sempre lá para resolver os problemas que apareciam. (E40) 
Foram apontadas situações circunstanciais pessoais que se conformaram como dificultadores da permanência:

Devido eu ter engravidado, minha gestação foi um pouco complicado [...]. (E10)

Tive muitos problemas porque eu tenho crianças, tenho gêmeos, são pequenas[...]. (E32)

Em relação ao trabalho, a área de atuação do aluno contribuiu para a sua permanência no curso. Além disso, a possibilidade de aplicação dos conhecimentos no trabalho também foi um estímulo.

80\% das atividades no meu trabalho são gerenciais[...] ]então não deixaria no meio do caminho [...]. (E2)

A maioria dos gestores, eles não tem uma formação, quando você tem o curso, você tem mais embasamento [...]. (E5)

Você conseguir enxergar aquilo que você está fazendo pra aplicar no trabalho incentiva você terminar[...]. (E18)

Todos os problemas que nós vivemos no nosso dia-a-dia, a gente consegue visualizar no curso, e consegue encontrar soluções [...]. (E22)

Verificou-se que a interação, na perspectiva do aprendizado compartilhado junto aos colegas de trabalho, fortaleceu a motivação dos alunos na continuidade do curso:

Eu levava alguns pontos do curso pra discutir com elas e contribuía para eu participar dos fóruns, para eu estar realizando as tarefas [...]. (E29)

Por estar trocando algumas ideias, as pessoas que trabalham comigo participaram também ativamente do curso, junto [...]. (E47)

Os entrevistados também reconheceram aspectos do trabalho que se conformaram como dificultadores da permanência. Destacaram o excesso de atividades no trabalho e os vários vínculos empregatícios.

A gente atua no cargo de gestão, não tem horário pra entrar e nem para sair, fica difícil conciliar as atividades do curso e do trabalho [...]. (E52)

Tenho outro vínculo, então eu fazia sempre as atividades à noite, no domingo, era o tempo que eu tinha [...]. (E3)

Além disso, foi exposto certo desconforto junto à equipe de trabalho em relação aos participantes do curso:

As pessoas ficam um pouco inseguras com a gente[...]como você está capacitando para aquela função, então você desempenha melhor [...]. (E5)

Ah eles ficam com inveja de mim[...]todos queriam estar no meu lugar [...]. (E28)

O contexto familiar foi apontado como fator motivador da permanência e alguns familiares foram reconhecidos pela sua contribuição no desenvolvimento direto das atividades do curso.

Muitas vezes eu pensei em desistir, ficava desmotivado, mas aí principalmente minha esposa me dava muito apoio, e estou concluindo[...]. (E12)

Tenho uma irmã, ela sempre me ajudava nas tarefas[...].(E34)

O fato de os familiares também estudarem e entenderem as ausências do aluno no convívio familiar foi importante para o incentivo à permanência.

Todos nós lá em casa estudamos, os filhos estudam, eu estudo e meu marido estuda[...] um é cúmplice do outro. (E2)

Eles às vezes queriam viajar, sair, eu dizia não, porque estou estudando [...]. (E3)

No final de semana que eu poderia estar visitando minha família eu não fui, e a minha família 


\section{Estar-em-rede}

Em se tratando do uso de tecnologias da informação em saúde, alguns entrevistados pontuaram que o uso da plataforma virtual e o e-mail foram facilitadores para a realização do curso.

A facilidade de manuseio da plataforma, isso aí eu achei que foi um fator facilitador [...]. (E24)

A estratégia que eu utilizei muito foi o e-mail [...]. (E8)

A dificuldade de alguns com o manuseio de computadores foi reconhecida. Além disso, o acesso à internet foi citado como uma dificuldade, sobretudo quando relacionado à conectividade:

Não sei utilizar direito o computador [...]. (E38)

A internet aqui, por ser cidade pequena deixa muito a desejar, porque tudo tem que ser feito na internet[...]. (E11)

Quanto à interação entre docentes e discentes, alguns entrevistados sentiram-se desmotivados pela ausência física do professor, sentiram a necessidade do contato físico, do encontro presencial, do convívio e também destacaram a falta de retorno às perguntas de docentes e tutores.

Eu acho que por ser a distância a gente acaba sentindo a falta dos professores[...]. (E36)

Eu logo respondia e não tinha o retorno da mesma forma [...]. (E8)

Senti falta desse contato, com o colega [...]eu sinto falta de reunir[...]pra discutir rapidamente aquilo que foi estudado no decorrer, e nem sempre a gente consegue esclarecer[...]. (E16)

O tutor foi reconhecido como incentivador para a permanência no curso e também como orientador na aplicabilidade do conhecimento na prática:

O tutor sempre me incentivou, e isso faz a gente continuar participando do curso [...]. (E33)

O tutor me ajudou muito, mostrou que eu poderia utilizar de situações da gestão para incluir no consórcio, então eu consegui com a ajuda do tutor [...]. (E15)

No que diz respeito à interação entre os discentes, o uso do fórum de discussão se destacou como um elemento potencializador de trocas de conteúdo, aprendizado compartilhado e aproximação entre os participantes, o que reforçou a permanência.

O fórum, ele obrigava a gente a questionar, entendeu? a buscar [...] los outros colegas falavam lá no fórum, postavam [...]te dá várias amplificações [...]. (E34)

Eu gostei da parte entre o fórum temático e o de discussão [...]é um curso a distância, mas ao mesmo tempo você acaba tendo contato com todos [...]. (E42)

\section{Condições para a permanência}

Sobre o compromisso pessoal, verificamos algumas características inerentes à própria personalidade do aluno como potencializadoras da permanência no curso: a sua determinação, o desejo em adquirir conhecimento e o fato de gostar de trabalhar na área de gestão em saúde.

Eu não sou de desistir das coisas no meio do caminho não, quando eu começo, eu me dedico para chegar até $o$ final [...]. (E2)

É a mesma ideia de quando eu quis começar o curso, aprimorar meus conhecimentos[...]então eu quis fazer até o final[...]. (E45)

O fato de eu gostar dessa área de gestão em saúde facilitou bastante pra que eu pudesse concluir [...]. 
No que tange à credibilidade institucional, algumas características peculiares do curso foram apontadas como motivações da permanência dos alunos: a gratuidade do curso, o fato de ser ofertado na modalidade a distância, a flexibilidade de horários e locais para o estudo.

Só estou aqui devido à gratuidade do curso[...]. (E12)

A facilidade de estudar em casa tem me motivado muito, bem melhor[...]. (E27)

A flexibilidade de nós podermos fazer o próprio horário [...]. (E48)

Se por um acaso fosse aula presencial eu não poderia estar presente [...]. (E11)

Houve também o reconhecimento da credibilidade do curso e o fato de ser ofertado por uma universidade pública como importante para a permanência. Além disso, a concorrência para ingressar no curso é vista como um fator de estímulo à permanência.

Com o passar do tempo vi a seriedade do curso[...] a credibilidade do curso foi o que mais me incentivou a permanecer e concluir[...]. (E10)

Uma faculdade com nome, faculdade federal no meu currículo acadêmico, isso pra mim é ótimo [...]. (E34)

Eu achei uma oportunidade muito boa[...]porque aqui em Santa Izabel o curso é muito concorrido [...]. (E42)

Destacou-se a facilidade de contato com a coordenação, organização, sua compreensão sobre os problemas vivenciados pelo aluno e sua prontidão em responder as demandas.

A acessibilidade à coordenação em obter as respostas rápido. Achei tranquilo [...]. (E30)

Compreensão por parte da coordenação dos problemas pessoais que eu tinha[...]. (E8)

Eu acho eles de extrema organização, tudo aquilo que foi planejado foi concluído dentro do tempo e, sempre nos informando todas as atividades que iriam ser realizadas[...]. (E10)

A didática do curso e o seu material, apesar da necessidade de melhorias, também foram lembrados como incentivadores da permanência.

A didática do curso também eu gostei muito, isso me fez permanecer[...]. (E3)

O material didático me ajudou muito, me estimulou [...]. (E2)

Eu senti falta do material impresso para estudar[...]você receber a apostila é melhor, eu acredito que há um envolvimento maior[...]. (E15)

O conteúdo das disciplinas do curso também foi reconhecido como um fator de motivação para a permanência.

À medida que eu fui conhecendo o conteúdo do curso, eu fui me interessando, foi onde eu fui permanecendo até a conclusão[...]. (E11)

Desde o momento que nós vimos o conteúdo do curso, as matérias, nós vimos que estava interessante manter nosso esforço [...]. (E33)

A flexibilidade no cumprimento das atividades acadêmicas facilitou a conclusão do curso.

Fiquei de recuperação na primeira etapa, então eu não consegui atingir os 60\%, eu tive uma segunda chance de estar concluindo, então isso facilitou para gente [...]. (E10)

A data que eu não consegui entregar meu trabalho sempre tinha lá, uma nova data[...]porque senão, eu não teria condições de estar concluindo [...]. (E10) 


\section{- DISCUSSÃO}

A família, de forma predominante, foi reconhecida pelos alunos como um suporte importante para o desenvolvimento do curso. Alunos e familiares se inter-relacionam, ajudam-se mutuamente, influenciam-se, pois esse é o contexto em que estão inseridos, e que também se materializa no curso em desenvolvimento, mesmo na modalidade a distância. Estes achados reforçam a constatação de que os alunos que procuram a educação a distância, em sua maioria, são adultos e estão na condição de pais de família e não na condição de filhos $^{(8)}$. Resultados semelhantes foram verificados no perfil dos alunos deste estudo, em sua maioria do gênero feminino, com vínculo empregatício e casado.

Desta forma,os alunos trazem sob sua responsabilidade as atribuições que emergem do contexto familiar, e que podem influenciar o desempenho no curso $^{(12-13)}$. Apesar de elementos relacionados aos aspectos contextuais favorecerem a permanência, também foram reconhecidas dificuldades que poderiam prejudicá-la. Entretanto, os alunos apontaram estratégias para suplantar essas dificuldades: autodisciplina, automotivação e a busca de apoio no polo presencial.

O trabalho e as relações, nesse contexto, também foram reconhecidos como influenciadores da permanência. As motivações, a relação entre teoria e prática, bem como o envolvimento dos colegas influenciaram a permanência. $O$ trabalho está no rol de fatores que têm grande influência (positiva ou negativa) sobre a permanência de alunos em cursos na modalidade a distância ${ }^{(8)}$. Se o conteúdo aprendido no curso for aplicável ao contexto profissional do aluno, isso pode facilitar a conciliação entre trabalho e estudo, pois tornam o aprendizado significativo, aplicável e solidário, contribuindo para a permanência ${ }^{(12,14)}$.

A EaD propõe elementos tais como a autonomia do aprendizado, a colaboração em rede e a postura ativa do indivíduo que aprende ${ }^{(15)}$. Esses elementos são fundamentais para a instrumentalização da gestão dos serviços de saúde com vistas a suplantar desafios, neste contexto: o financiamento, a mudança de modelo assistencial, o controle social, a capacidade gerencial descentralizada, dentre outros.

O debate em torno da educação permanente em saúde também reforça essa necessidade de qualificar o gestor numa perspectiva colaborativa, em rede e de forma crítico-reflexiva. Ressalta-se que os problemas que emergem do trabalho norteiam as experiências educativas e, para tanto, colaboram para o envolvimento de vários atores ${ }^{(8,15-16)}$.

Verificou-se que as possibilidades de interações entre aluno/tutor/professor influenciaram a decisão por permanecer no curso. O tutor foi reconhecido como um ator importante, de mediação e incentivo, bem como foi apontada a necessidade (dependência) da presença física do professor e também da interação presencial entre os próprios alunos.

Assim, no que tange ao papel dos tutores, manifestou-se a sua presencialidade no contexto virtual, e isso foi importante para a permanência dos alunos. Por outro lado, nem sempre se manifestou de forma favorável. A presencialidade no contexto virtual gera o sentimento de pertencimento a um grupo e é um elemento necessário para potencializar a permanência ${ }^{(8,13)}$.

Neste processo, a conservação de acesso de comunicação permanente com os professores/tutores permite a retroalimentação do processo de ensino-aprendizagem, à medida que as atividades são realizadas ${ }^{(17)}$, tornando-se essencial para a permanência no curso. O diálogo é a premissa primordial para a formação da consciência crítica, sendo construído na relação entre as pessoas ${ }^{(18)}$.

No ambiente virtual, o tutor deve manter diálogo efetivo com os estudantes, proporcionando interesse mútuo, mas também conservando a linha de afeto que os torne parte integrante do processo $^{(17-18)}$. Isso se traduz em desenvolvimento da identidade cultural relacionada a determinado grupo ou comunidade e suas relações (conexões), as quais se estabelecem nesse espaço colaborativo ${ }^{(8)}$, impactando diretamente na adesão e na permanência deste participante ao longo do curso.

As habilidades com as tecnologias de informação foram manifestas nas entrevistas dos participantes como fator de influência na permanência. O fórum emergiu como ferramenta tecnológica do ambiente virtual, permitindo a socialização e o aprendizado colaborativo numa perspectiva em 
rede (trocas, aproximações, diálogos). É importante salientar que os tutores têm papel importante no desenvolvimento de habilidades técnicas no uso do ambiente virtual, considerando sempre os desafios de aprendizagem on-line ${ }^{(19)}$.

Quanto às condições de permanência no curso, foi possível afirmar que há situações importantes que estão diretamente relacionadas ao aluno, à estrutura e à gestão do curso. Esses achados estão alinhados com o fato de que o aluno permanente é aquele que encontra na IES o interesse, as motivações e as condições favoráveis ao desenvolvimento de suas atividades ${ }^{(8)}$. Contudo, é importante explicitar as concepções pedagógicas do curso, prover a infraestrutura adequada para seu funcionamento e estruturar seu gerenciamento, visando garantir ao aluno uma trajetória adequada no processo de ensino-aprendizagem ${ }^{(14)}$.

A tríade compromisso pessoal, integração acadêmica e credibilidade institucional necessita ser potencializada no curso, promovendo assim as condições favoráveis de permanência do aluno na $\mathrm{EaD}^{(1,8)}$.

Reconhecemos como limitações do estudo a sua capacidade de generalizações por se tratar de um estudo de caso que possui um contexto e suas especificidades. Também reconhecemos a dificuldade em captar alunos permanentes para a participação do estudo.

\section{- CONCLUSÃO}

Percebe-se que são vários os fatores que influenciam na permanência do aluno na modalidade a distância. Tais fatores se relacionam desde as convicções e interesses pessoais do aluno até a organização político-pedagógica do curso e da instituição que o oferta. O fato de o aluno estar imerso em rede colaborativa e solidária pode proporcionar barreiras para o desenvolvimento do seu aprendizado, bem como potencializa seu aprimoramento e sua aplicabilidade nas práticas profissionais.

Estas constatações conformam-se como contribuições por elucidarem aspectos que devem ser considerados no processo de elaboração e avaliação de cursos na modalidade a distância no contexto da saúde. Além disso, contribuem para o norteamento de outros estudos que desvelem ainda mais a temática da permanência.

Considerando a continuidade da oferta do curso de especialização de Gestão em Saúde, por meio do PNAP, também são necessários estudos avaliativos de tutores e professores, análise das práticas pedagógicas, análise de satisfação e desempenho dos envolvidos, bem como os impactos sobre a gestão dos serviços de saúde.

\section{REFERÊNCIAS}

1. Coordenação de Aperfeiçoamento de Pessoal de Nível Superior (CAPES). Programa Nacional de Formação em Administração Pública no Âmbito do Sistema Universidade Aberta do Brasil. Edital no 01, de 27 de abril de 2009. [Internet] Brasília; 2009 [acesso em 31 mar 2014]. Disponível: http://www.capes.gov.br/bolsas/programasespeciais/2617.

2. Coordenação de Aperfeiçoamento de Pessoal de Nível Superior (CAPES). Relatório de gestão do exercício de 2013. [Internet] 2014 [acesso em 11 nov 2014]. Disponível:http://www.capes.gov.br/images/stories/download/ Contas_Publicas/Relatorio-de-Gestao-2013.pdf.

3. Hart C. Factors associated with student persistence in an online program of study: a reviewof the literature. JILR. [Internet]2012;11(1) [acesso em 20 nov 2014].Disponível: https://pdfs.semanticscholar.org/79be/1d3cce424c 775082cc9dc515c83f09faec98.pdf.

4. Diniz UM. Evasão no curso de graduação a distância: um estudo no bacharelado de administração pública na UFPA [dissertação]. Belém (PA): Universidade Federal do Pará; 2013.

5. Grohmann MZ,Riss LA, BattistellaLF.Avaliação dos cursos do programa nacional de formação de administração pública (PNAP): a visão dos discentes de uma instituição federal de ensino superior.Rev. GUAL. [Internet]2014;7(2) 
[acesso em 20 jan 2015]. Disponível: http://dx.doi.org/10.5007/1983-4535.2014v7n2p17.

6. Croxton RA. The role of interactivity in student satisfaction and persistence in online learning.MERLOTJOLT. [Internet]2014;10(2) [acesso em 19jan 2015]. Disponível: jolt.merlot.org/vol10no2/croxton_0614.pdf.

7. Meneses PPM, Zerbini T, Martins LB. Determinantes situacionais e individuais da aprendizagem em ensino a distância: desenvolvimento de escala. Rev. PSICO. [Internet] 2012;43(2) [acesso em 19nov 2014]. Disponível: http://revistaseletronicas.pucrs.br/ojs/index.php/revistapsico/article/view/11698/8044.

8. Ramos e Silva JA. A permanência de alunos nos cursos presenciais a distância de administração: contribuições para gestão acadêmica[tese]. Rio de Janeiro (RJ): Escola Brasileira de Administração Pública e de Empresas; 2012.

9. Minayo MCS. Análise qualitativa: teoria, passos e fidedignidade. Ciênc.saúde coletiva. [Internet]2012;17(3) [acesso em 02 nov 2014]. Disponível: http://dx.doi.org/10.1590/S1413-81232012000300007.

10. Yin RK. Estudo de caso: planejamento e métodos. $5^{a}$ ed. Porto Alegre: Bookman; 2015.

11. Bardin L. Análise de Conteúdo. 4ªed. Lisboa: Edições 70; 2011.

12. Ramos e Silva JA, de Oliveira FB, Mourão L. Fatores que levaram à permanência e ao sucesso dos alunos em um curso a distância. São Luís: ABED; 2013.

13. Ward-Smith P,Schmer C, Peterson J, Hart C. Persistence among graduate nursing students enrolled in an online course. J Nurs Educ. [Internet] 2013;3(9) [acessoem 02 nov 2014]. Disponível: http://dx.doi.org/10.5430/ jnep.v3n9p48.

14. Moore MG, Kearsley G. Educação a distância: sistemas de aprendizagem on-line. $3^{a}$ ed. São Paulo: CengageLearning; 2013.

15. Rangel-S ML, Barbosa AO, Riccio NCR, de Souza JS.Redes de aprendizagem colaborativa: contribuição da educação a distância no processo de qualificação de gestores do Sistema Único de Saúde - SUS. Interface, Comun., Saúde, Educ. [Internet] 2012;16(41) [acesso em 02jan 2014]. Disponível: http://dx.doi.org/10.1590/S141432832012005000031.

16. de Macêdo NB, de Albuquerque PC,de Medeiros KR.O desafio da implementação da educação permanente na gestão da educação na saúde.Trab.educ. saúde. [Internet]2014;12(2) [acesso em 02jan 2014]. Disponível:http:// dx.doi.org/10.1590/S1981-77462014000200010.

17. Martins-Melo FR, Lima MS, Ramos Júnior AN, Heukelbach J, Campo MOC. Modalidade de educação a distância na formação profissional em saúde da família: relatode experiência. Rev.Bras.Med.Fam. Comunidade. [Internet] 2014;9(30) [acesso em 18nov 2015]. Disponível: http://dx.doi.org/10.5712/rbmfc9(30)486.

18. Freire P. Pedagogia da autonomia: saberes necessários à prática educativa. $25^{a}$ ed. São Paulo: Paz e Terra; 2008.

19. Aguilar JAM. Blended learning and the language teacher: a literature review. Colomb.Appl.Linguist. J. [Internet]2012;14(2) [acesso em 10nov 2015]. Disponível:http://www.scielo.org.co/pdf/calj/v14n2/v14n2a11.pdf. 